International Journal of Engineering \& Technology, $7(2.21)(2018)$ 190-193
International Journal of Engineering \& Technology
SPC
Website: www.sciencepubco.com/index.php/IJET
Research paper

\title{
A novel technique of dynamic speed control for buck boost converter fed BLDC motor drive
}

\author{
K. Sasikala ${ }^{*}$, R. Krishna Kumar² \\ ${ }^{I}$ Research Scholar \& Assistant Professor, Department of Electrical Engineering, Vels Institute of Science, \\ Technology and Advanced Studies (VISTAS), Chennai. \\ ${ }^{2}$ Associate Professor, Department of Electrical Engineering, Vels Institute of Science, \\ Technology and Advanced Studies (VISTAS), Chennai. \\ *Corresponding authorE-mail: skala.se@velsuniv.ac.in
}

\begin{abstract}
This paper mainly impacts on a bridgeless buck boost converter fed Brush Less Direct Current (BLDC) motor drive with Power Factor Correction (PFC) which is low cost and well suitable for low power applications. The speed of the BLDC motor is controlled by adjusting the Voltage Source Inverter's dc link voltage which is then employed along with a distinct voltage sensor. Thus the fundamental frequency switching of VSI operation becomes quite ease with BLDC motor's electronic turn off which provides minimal switching losses. An acceptable performance is attained for speed control having power quality indicators within the allowable limits. To end with the suggested drive's prototype model has been implemented to evaluate and confirm the suggested BLDC motor drive's performance for various speed controls with enhanced AC main's power quality.
\end{abstract}

Keywords: Bridgeless Brush less Direct Current (BLDC), Voltage Source Inverter (VSI), Power Factor Correction (PFC).

\section{Introduction}

A Bridgeless buck boost converter has been configured and it is been suggested in which the bridge rectifier is eliminated and the conduction losses occurred with it is also been reduced. A design of Power Factor Corrected Bridgeless buck boost converter is done in such a way where it operates in Discontinuous Current Mode and delivers essential PFC at ac supply. The suggested drive's performance is measured by varying the speed and the supply voltages with enhanced ac main's power quality.

\section{Related works}

Single-phase Permanent Magnet BLDC motors have been used widely for low cost applications. The author suggests a singlephase BLDC drive which is used to back fit the vacuum cleaner. When the conventional control technique is used, then the EMF and current waveforms will be out of phase because of the high winding inductance and of high operation speed. Consequently, a negative torque component is induced and the overall torque is significantly reduced. In order to make the most of the motor power in a denser manner and to reduce the motor peak phase current reduction of the power device ratings for high-speed applications is done. In order to support with, two alternative turn off strategies are studied - one is using the phase turn off advancing technique and another is using conducting pulse-width control. [1]

A systematic energy-management system using Neural Networks (NNs) for hybrid electric vehicles (HEVs) was developed and evaluated. The vehicle energy demand is reduced by the system and with various primal power sources viz fuel cells, micro turbines can be worked along with it. The system can also work with the power supply having a minimal ability to pick up energy from the regenerative braking or with an insufficient power capacity for a speedy acceleration. [2]

A new driver for a $1-\phi$ BLDC motor having a hybrid parallel and/or series winding structure is suggested in this paper. The directions of the stator structure and the winding symbols are described and the suggested parallel and/or series winding steps are elucidated. A sufficient inverter driving circuit, having the ability to acquire the benefits of this structure simultaneously, is also been described. Finally, the complete system of the hybrid BrushLess Direct Current along with the suggested driving circuit is then executed in order to confirm the work which results from the suggested driver and structure. [3]

A single-stage PFC DC-DC Cuk converter for a PermanentMagnet Brush Less DC Motor fed through a diode rectifier from a1 $-\Phi$ AC mains is dealt in this paper. To operate the PermanentMagnet (PM) Brush Less DC Motor driving an air-conditioner compressor, a three phase VSI which acts as an electronic Commutator is also been used. The optimal air-conditioning is achieved by controlling the speed of the compressor by applying the voltage at dc link equivalent to the preferred speed of the Permanent-Magnet Brush Less DC Motor (PMBLDC) concept. By adding the rate limiter in the reference dc link voltage, it impacts the step transformance in the reference speed, the stator currents of the PMBLDCM will be controlled within the allowable limits. [4]

Power Quality improvement, viz reduced Total Harmonic Distortion (THD), PFC at input AC supply is maximally attained by Solid-state switch-mode converters. Also an accurate regulated DC output is obtained with boost, buck, buck-boost configurations. A detailed review of design features, selection of components, control approaches, Improved Power Quality Converters (IPQCs) configuration and their selection for precise applications are dealt in this paper. A wide range of IPQC technology has been provided to researchers, application 
engineers and designers who will be working on switched-mode AC-DC converters. [5]

Switched mode AC to DC converters having Boost, Buck and Buck-Boost configurations will deliver power quality improvement viz. PFC at AC supply. It also provides reduced Total Harmonic Distortion (THD) and regulated DC output voltage which will be fed for loads ranging between few watts and kilowatts. A detailed report on PFC 1- $\phi$ AC-DC converter configurations, component selection, design concerns and power quality concerns and improvements are given in the paper. [6]

\section{Proposed system}

Application demanding a broad choice of dc link voltage controlled buck and boost mode prefers a buck-boost converter configuration which suites various BL converter topologies with limited working range of dc link voltage by increasing or decreasing the voltage. Since the suggested Bridgeless buck boost converter uses three switches which are not effective solutions on cost basis. In the literature it is reported that BL SEPIC and Cuk converters needs large number of components which in turn increases the losses. A BridgeLess buck boost converter fed motor drive is suggested for its enhancement on AC main's power quality having lesser no of components.

\section{BLDC motor}

Brushless dc motors are preferred in industrial automation industries, consumer, appliance, automotive, aerospace and medical field. Since the mechanical commentators, brushes and the permanent magnet rotor are not present in brushless de motors, it gains more advantages in compared to brush dc and induction motor.

Implicit PFC at ac supply is attained when the suggested Bridgeless buck boost converter based VSI fed BLDC motor drive's parameters are designed and operated in Discontinuous Current Mode (DCM).

Voltage Source Inverter's de link voltage control in Bridgeless buck boost converter regulates the speed of BLDC motor. Electronic turn off of the BLDC motor with low frequency operation of VSI minimizes the switching losses. With enhancement in ac main's power quality for various speed controls, the suggested drive's performance is been measured. In addition to the results obtained by varying the supply voltage at the input, it determines the performance under practical conditions. Heat sink design and the switch rating are found by measuring the voltage stress and current stress in the Power Factor Corrected converter. At last, the BrushLess Direct Current motor drive is realized and implemented in hardware for various speed controls which enhances power quality.

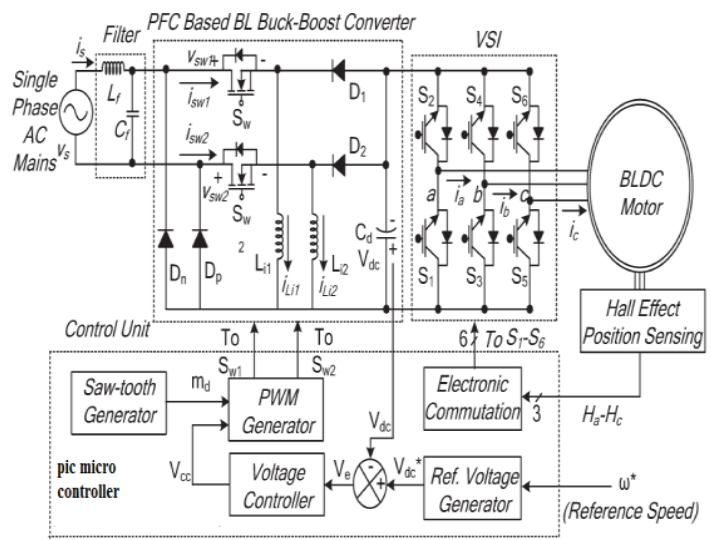

Fig. 4: Circuit diagram of BLDC motor drive
Switches Sw1 and Sw2 in the suggested converter are operated in both the half cycles of the input voltage. The energy transfer to dc link capacitor $\mathrm{C}_{\mathrm{d}}$ is obtained by the conduction of $\mathrm{Sw} 1, \mathrm{~L}_{\mathrm{i}}$, and $\mathrm{D}_{1}$ and $D_{p}$ in the positive cycle of the input voltage as indicated in Fig.4. Likewise $\mathrm{Sw}_{2}, \mathrm{~L}_{\mathrm{i}}$, and $\mathrm{D}_{2}$ and $\mathrm{D}_{\mathrm{n}}$ operate in the negative cycle as indicated in Fig.4. The inductor current $\mathrm{L}_{\mathrm{i}}$ is discontinuous for specific switching period under the DCM operation of the Bridgeless buck boost converter. The different parameter waveforms for the positive as well as negative cycles of input voltage are illustrated in Fig. 3.4

\section{Modes of operation}

\subsection{Mode 1}

Mode 1: In this mode, the conduction of switch $S w 1$ charges the inductor $L_{i 1}$, which increases inductor current $i \mathrm{~L}_{\mathrm{i} 1}$ as indicated in Fig.5.1. The input side circuitry is completed by Diode $D_{p}$ and VSI fed BLDC motor discharges the dc link capacitor $C_{d}$.

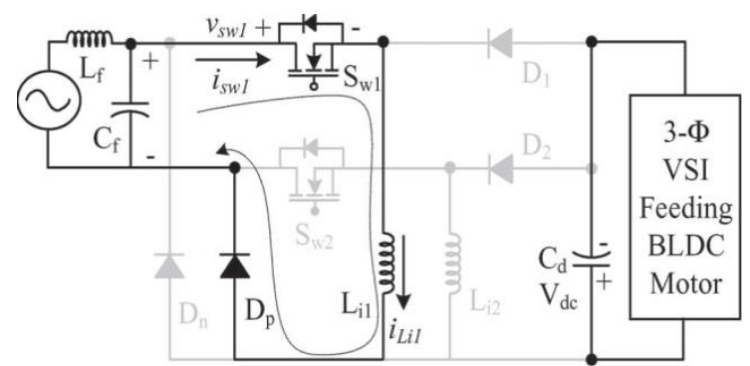

Fig. 5.1: Mode 1 Operation

\subsection{Mode 2}

Mode 2: When the switch $S w 1$ turns off, the transfer of energy from the $L_{i 1}$, inductor to $C_{d}$ dc link capacitor is done till the entire inductor energy is discharged. The inductor current $i \mathrm{~L}_{\mathrm{i} 1}$ reaches zero.

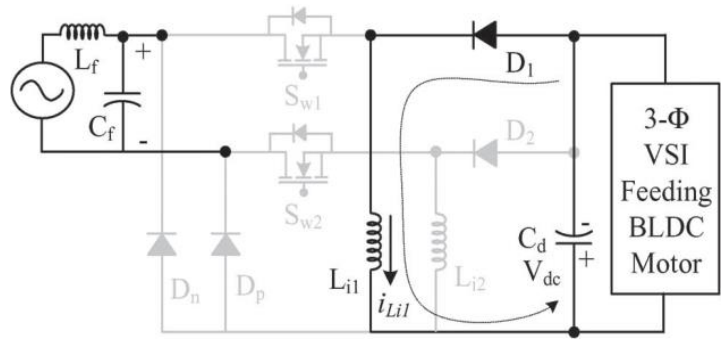

Fig. 5.2: Mode 2 Operation

\subsection{Mode 3}

Mode 3: The discontinuous conduction of the inductor $L_{i 1}$ occurs, i.e. when the energy in the inductor is zero, which in turn zero current $i \mathrm{~L}_{\mathrm{i} 1}$ appears for the remaining switching period. In this mode, all switches and diodes are in non conduction mode and the energy is supplied by the de link capacitor $C_{d}$ to the load. Hence the voltage across $C_{d}, V \mathrm{dc}$ starts reducing. After a complete switching cycle, the same operation repeats as the switch $S w 1$ turns on. 


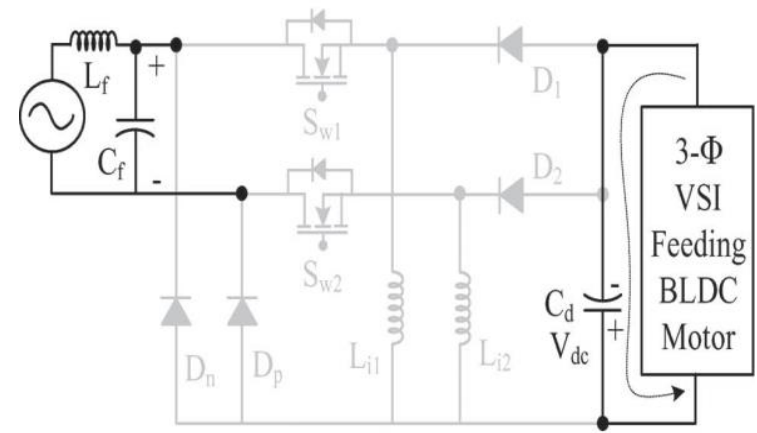

Fig. 5.3: Mode 3 operation

\subsection{Waveform of mode $1,2,3$}

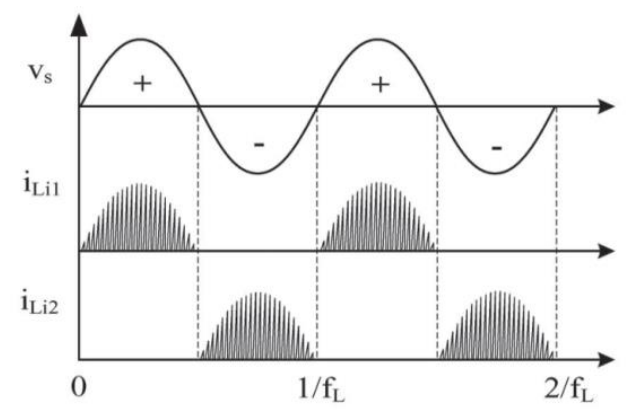

Fig. 5.4: Waveforms for positive as well as negative half cycles of input voltage

\section{Hardware circuit diagram and its snapshot}

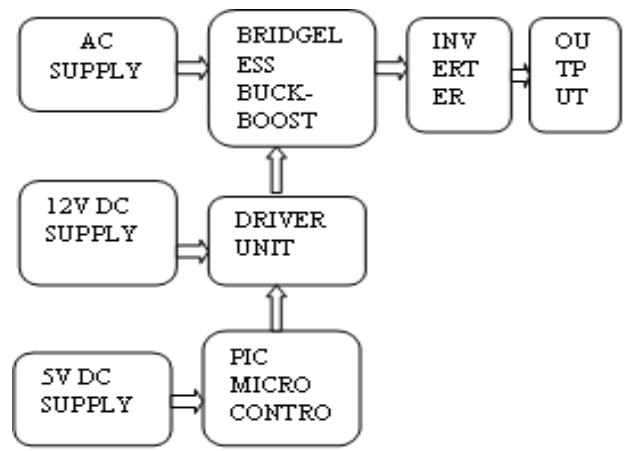

Fig. 6.1: Block diagram of hardware circuit

Fig 6.1 shows the hardware block diagram circuit. DC supply ranging from $+5 \mathrm{v}$ to $\_+12$ is used in this hardware circuit. A $230 \mathrm{v}-50 \mathrm{~Hz}$ supply is used which is stepped down, rectified, filtered and regulated the voltage. An IC7812 provides $+12 \mathrm{v}$ DC supply which is given as input to the driver circuit. Similarly IC 7805 provides $+5 \mathrm{~V}$ Regulated Power Supply for Microcontroller Unit. PIC16FXXX microcontroller is used to drive the driver unit. The Ac supply is given to BL Buck-Boost converter whose operations are dealt earlier and its output is given to an inverter which provides an AC output. Fig 6.2 shows the snapshot of hardware circuit.

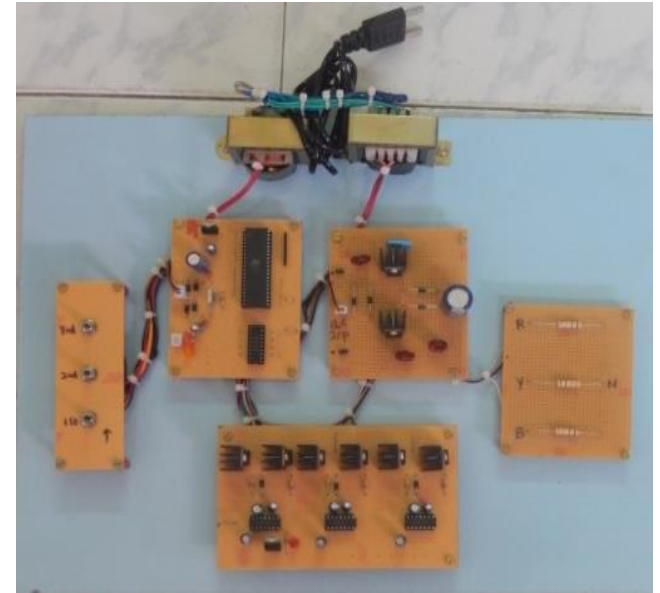

Fig. 6.2: Snapshot of hardware circuit

\section{Simulation results}

\subsection{Simulation of suggested BLDC motor drive}

The simulation of the suggested Brush Less Direct Current motor drive is done with MATLAB/Simulink software. Analysis of motor parameters viz electromagnetic torque $(\mathrm{Te})$, speed $(\mathrm{N})$ and stator current $\left(i_{a}\right)$ is carried out to check its proper functioning. Measurement of input voltage $\left(\mathrm{V}_{\mathrm{s}}\right)$, input current $\left(\mathrm{i}_{\mathrm{s}}\right)$, switch voltages ( $\mathrm{V}_{\mathrm{sw} 1}$ and $\left.\mathrm{Vsw} 2\right)$ and switch currents ( $i_{\mathrm{sw} 1}$ and $\left.\mathrm{i}_{\mathrm{sw} 2}\right)$, inductor's currents (i i $\mathrm{Li}_{1}$ and $\left.\mathrm{iLi} 2\right)$, dc link voltage $\left(\mathrm{V}_{\mathrm{dc}}\right)$ is done to evaluate its functioning. Fig.7.1. shows the suggested Brush Less Direct Current motor drive's performance at estimated conditions. In addition to the above parameters, power quality indicators viz PF and THD are also analyzed in order to determine the AC main's power quality.

\subsection{Steady state and dynamic performance}

The suggested BrushLess Direct Current motor drive's steadystate behavior for both cycles of input voltage at estimated condition is illustrated in Fig. 7.1. The obtained inductor currents (iLi1 and iLi2) which are discontinuous in nature indicate the DCM operation of the Bridgeless buck boost converter. The input current's harmonic spectrum at estimated and light load conditions, i.e., dc link voltages are also illustrated in Fig. 7.1 indicates that the obtained THD of input current is under the allowable limits. The dynamic behavior of the system is also illustrated in Fig 7.2.

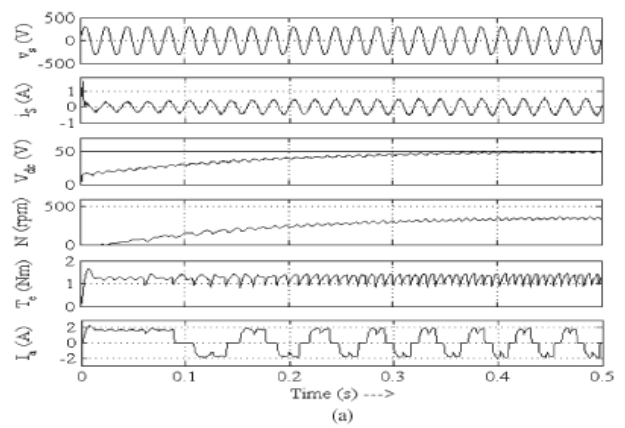

Fig. 7.1: Waveform for steady state performance 


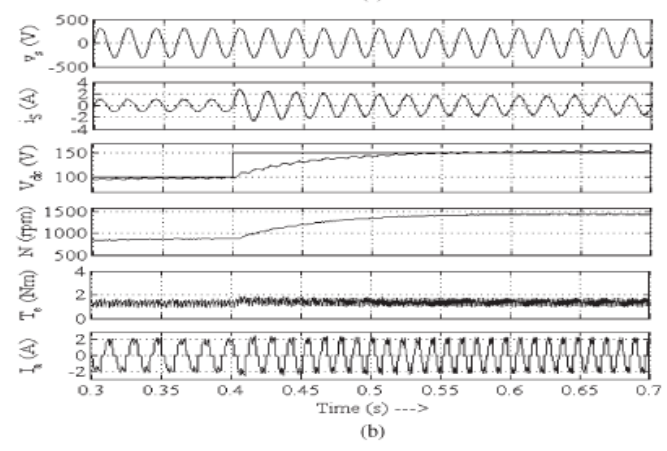

Fig. 7.2: Waveform for dynamic performance

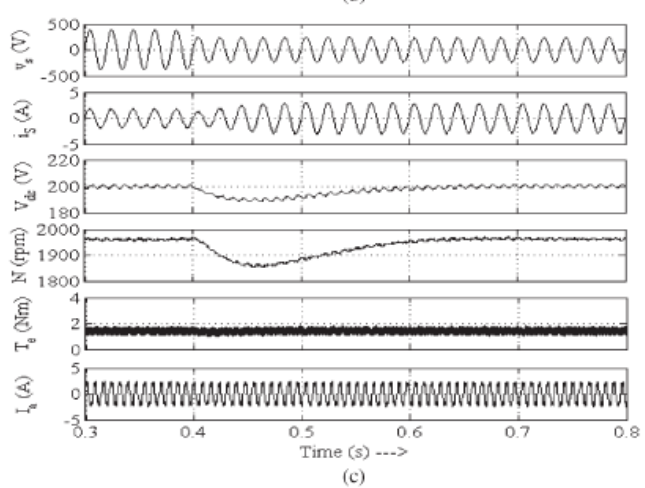

Fig. 7.3: The suggested system's dynamic performance

\section{Conclusion}

A Voltage Source Inverter fed BrushLess DC motor drive with Power Factor Corrected Bridgeless buck boost converter has been designed and is also aims at low power applications. A novel technique of speed control has been employed by adjusting the voltage. Implicit PFC at ac supply is attained when the suggested converter based BrushLess DC motor drive's parameters are designed and operated in Discontinuous Current Mode (DCM).The dc link voltage control of Voltage Source Inverter in suggested converter regulates the speed of BLDC motor. Electronic turn off of the Brushless DC motor with low frequency operation of VSI minimizes the switching losses. With enhancement in ac main's power quality for various speed controls, the suggested drive's performance is measured. An acceptable performance is attained for speed control having power quality indicators within the allowable limits. To end with the suggested drive's prototype model has been implemented to evaluate and confirm the suggested Brushless DC motor drive's performance for various speed controls which would have its enhancement on the AC main's power quality.

\section{Future scope}

For more accurate speed control of the BLDC Motor and make the response time to be more rapid and efficient, the control logic can be developed using Fuzzy Logic Algorithm.

\section{References}

[1] Xia CL, Permanent Magnet Brushless DC Motor Drives and Controls. Hoboken, NJ, USA: Wiley, (2012).

[2] Moreno J, Ortuzar ME \& Dixon JW, "Energy-management system for a hybrid electric vehicle, using ultra capacitors and neural networks", IEEE Trans. Ind. Electron., Vol.53, No.2, (2006), pp. 614-623.

[3] Chen Y, Chiu C, Jhang Y, Tang Z \& Liang R, "A driver for the single phase brushless dc fan motor with hybrid winding structure", IEEE Trans.Ind. Electron., Vol.60, No.10, (2013), pp.4369-4375.
[4] Huang X, Goodman A, Gerada C, Fang Y \& Lu Q, "A single sided matrix converter drive for a brushless dc motor in aerospace applications", IEEE Trans. Ind. Electron., Vol.59, No.9, (2012), pp.3542-3552.

[5] Toliyat HA \& Campbell S, DSP-Based Electromechanical Motion Control. Boca Raton, FL, USA: CRC Press, (2004).

[6] Pillay P \& Krishnan R. Modeling of permanent magnet motor drives", IEEE Trans. Ind. Electron., Vol.35, No.4, (1988), pp.537-541. 